\title{
DESIGN AND FABRICATION OF AUTONOMOUS AIRCRAFT DELIVERY, MONITORING AND SURVEILLANCE SYSTEM
}

\author{
CHANDRAKANTHA SHARMA B V $\mathrm{V}^{1}$, DR ASHOK B C ${ }^{2}$, DR S A MOHAN KRISHNA ${ }^{3}$, \\ ARUN C DIXIT ${ }^{4}$, ABHILASH $\mathrm{S}^{5}$, ASHISH $\mathbf{R}^{6}$ \& A D ABHAY \\ Department of Mechanical Engineering, VVCE, Mysuru, Karnataka, India
}

ABSTRACT
The constant need for a system to monitor, surveillance, react to situation appropriately based on the requirement in
emergency situation is a problem of past. In the modern age, highly equipped Unmanned Aerial Vehicles (UAVs) are used
in these emergency situations for collection of security, deep sea data and research and development. The unmanned
autonomous aircraft system is aimed to be weather proof of all terrain system capable of countering rough and harsh
conditions. The aircraft uses location data to drop relief material to stranded people who are far from reach. The aircraft
gets the input from the transmitter to the mounted receiver on the system that processes the signal to control the motor,
ailerons etc. Numerous tests on prototypes with lot of surveys and discussions a final model was given. It was further
checked with analysis and testing, which showed the data regarding limitations and capabilities of UAV as well.
KEYWORDS: UAV, Aircraft, Transmitter, Motor and Surveys

Received: Jun 08, 2020; Accepted: Jun 28, 2020; Published: Aug 21, 2020; Paper Id.: IJMPERDJUN2020850

\section{INTRODUCTION}

One of the most significant difficulties faced when responding to rapid onset disasters, like floods, earthquakes and hurricanes is to understand the requirements of the affected population accurately and swiftly. Current direct analysis methods are time consuming and the captured data is often not conducted in a systematic way with the locations sampled not being geographically representative (too clustered and too few), and the subsequent reports being produced too late. Unmanned aerial vehicle is defined as powered aerial vehicle that does not carry human operator, uses aerodynamic forces to provide lift, can fly autonomously and can carry lethal or non-lethal payload.

The new age of autonomous aircraft system is designed in such a way that thrust force is reduced payload carrying capacity is increased. Calculations are based on system is designed to be light weight and robust and hence its speed is much faster when compared to a drone of similar load carrying capacity. It is also installed with a surveillance camera which is used for the purpose of locating people during natural calamities and provides them with relief material. The system has quick response to control inputs given with high precession and satisfactory range of operation. The system does not occupy much space and also our aircraft system can be hand launched and all the materials are available at an economical price [1 - 12].

The major advantage of this system is that it is swift and accurate and it does not leave any carbon footprints when it runs. The products are delivered in small cardboard boxes there is no need for its disposal and also parachutes are used to drop the products at less time and safe speed. 
Mohammad H Sadraey's book on “Aircraft Design: A Systems Engineering approach”[11], Solid works package is used for the purpose of CAD design. XFLR5 is the software package in which aerodynamic testing.

\section{LITERATURE SURVEY}

The team spent a lot of time on survey of literatures at initial stage itself so that the need of autonomous system is analyzed and is accordingly accomplished. The autonomous aircraft system utilizes in site real time data sensing, aerial refueling scope, highly integrated radar to create versatile accurate system with the changing condition the author lets them be treated as individual segments for better handling. The navigation is being made on landmark based system for constant position and correction. The crosswire effects complicate aircraft landing and takeoff procedures. The author utilizes time domain relations in the received telemetry signals and uses data of aircraft dynamics and mechanics to obtain data. The team finally decided to go with this particular aircraft after survey of recent advances of small-scale UAV platform which stated them to be best comprising of onboard processing units, sensors etc. making them most useful.

\section{METHODOLOGY}

The system methodology is based on the literature survey and also based on our system requirement like takeoff weight, length of the wing, weight of the system etc.

\section{Design Methodology}

\section{Planform Selection}

For calculating amount of wing surface area required and for generating enough lift the main parameter is maximum takeoff weight. The team found value of the maximum take-off weight and wing area was calculated. The wing can be of various geometries and it is decided based on the mission requirements. Some of the geometries considered in RC plane design are:[11]

- Rectangular Wing

- It has a taper ratio of one.

- Easy to manufacture.

- $\quad$ Elliptical Wing

- It has very good efficiency.

- It is very difficult to fabricate and time consuming.

- It is prone to tip stalling.

- Swept wing

- Less drag.

- Difficult to manufacture.

- Design of structural strength is difficult. 
The team decided to proceed with a rectangular high winger, mono wing configuration due to the following parameters:

- $\quad$ Rectangular Wing

- Easy to build or fabricate.

- It has high performance with respect to the investments occurring along with it.

- Easy to balance the wing.

- $\quad$ High Winger

- It is easier to load and unload cargo.

- Facilitatesan aircraft control as a glider, since the aircraft center of gravity is lower than the wing.

- The wing will produce more lift compared to mid and low wing, since two parts of the wing are being attached to the top part of the fuselage. For the same condition, the aircraft will be having lower stall speed, since $\mathrm{CL}_{\max }$ will be higher.

- The aerodynamic shape of fuselage section in the under part can be smoother.

- There is abundant space inside the fuselage for cargo setup to be made.

- Mono wing

- Lower weight

- Higher lift

\section{Wing Planform Calculations}

Based on the maximum take-off weight and assumed aircraft speed the wing planform area can be calculated by finding out wing loading.[11]

- Wing Loading assumed by the team $=8.25 \mathrm{~kg} / \mathrm{m}^{2}$.

- Wing loading=W/s

Where: $\mathrm{W}$ is the Maximum take-off weight.

$\mathrm{s}$ is the planform area

$$
\begin{aligned}
& 8.25=7 / \mathrm{s} \\
& \mathrm{s}=0.85 \mathrm{~m}^{2}
\end{aligned}
$$

\section{Aerodynamics}

After planform calculation an airfoil is needed to be selected. The main necessities for airfoil were high $\mathrm{C}_{\operatorname{lmax}}$, gentle stall and positive pitching moment to neutral, Max $\mathrm{C}_{\mathrm{l}} / \mathrm{C}_{\mathrm{d}}$, Reynolds number range and the ease of fabrication. 


\section{Calculation}

Reynolds Number

$$
\begin{aligned}
& \mathrm{R}_{\mathrm{e}}=\rho \times V t \times C \times \mu \\
& \mathrm{R}_{\mathrm{e}}=275477.843
\end{aligned}
$$

Where $\mathrm{C}=$ Chord length

$\rho=$ Density of air

$\mathrm{V}_{\mathrm{t}}=$ Turning velocity

$\mu=$ Dynamic Viscosity of air

For the above Reynolds number of 275477.843 multiple airfoils were considered.

The team selected the Eppler 423airfoil due the high lift generating capabilities. All the different data about Eppler 423 from Airfoil tools website were considered and analysed. The team also analysed the airfoil in XFLR5 for the different characteristics of it. The details of the polar graphs as per XFOIL analysis are as follows.

\section{Eppler 423 Polar Curves}

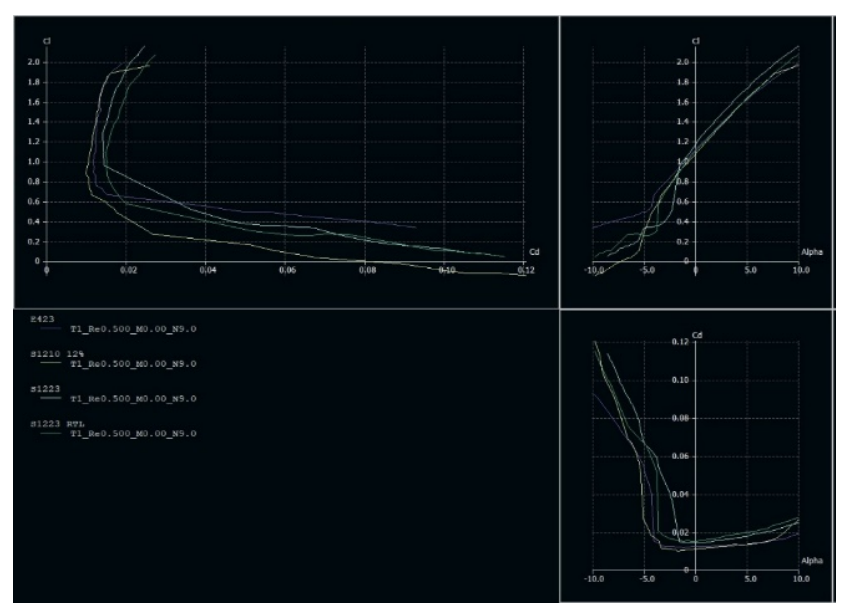

Figure 1: Eppler 423 Polar Curves.

In this graph the airfoil analysis was carried out and it's been found that the Eppler 423airfoil generates high lift with nominal drag and has very high effectiveness of aileron.

From the above polar graphs, the team determined the critical airfoil data such as:

$$
\begin{aligned}
& \mathrm{C}_{\mathrm{lo}}=1.1864, \mathrm{C}_{\mathrm{lmin}}=1.2420, \\
& \mathrm{C}_{\mathrm{dmin}}=0.01874, \mathrm{C}_{\mathrm{li}}=1.5826, \\
& \left(\mathrm{C}_{\mathrm{l}} / \mathrm{C}_{\mathrm{d}}\right)_{\max }=73.64, \\
& \mathrm{C}_{\operatorname{lmax}}=2.2919 \text { at } \alpha=13^{\circ}
\end{aligned}
$$




\section{DESIGN SPECIFICATIONS}

An aircraft is a combination of various parts having their own design and structure which serve various purpose. The prototype designed by the team provides vital information about changes to be before finalizing the design.

\section{Wing}

The wing fabricated for prototype involved the use of hardened thermocol, wooden sticks and Aluminium. Hot wire cutting method was adopted for manufacturing the wing. Three $12.7 \mathrm{~mm}$ rectangular cross section hollow Aluminium spar is introduced inside the wing for structural strength. The details are shown in the CAD model.

Calculations [11]

- The necessary planform area was calculated to be $\mathrm{s}=0.85 \mathrm{~m}^{2}$

- The team considered multiple Aspect Ratio and finalized it to be .

- $\quad$ Aspect Ratio $(\mathrm{AR})=\frac{\mathrm{b}^{2}}{\mathrm{a}}$

- $\quad \mathrm{B}=2.8$

- $\mathrm{s}=\mathrm{b} * \mathrm{c}$

- $\mathrm{c}=\mathrm{s} / \mathrm{b}=0.406 \mathrm{~m}$

For ease of fabrication chord length is assumed to be $0.4 \mathrm{~m}$

Where: $\mathrm{s}=$ Planform Area

- $\mathrm{c}=$ Chord length

- $\mathrm{b}=$ Span

- $\quad \mathrm{AR}=$ Aspect Ratio

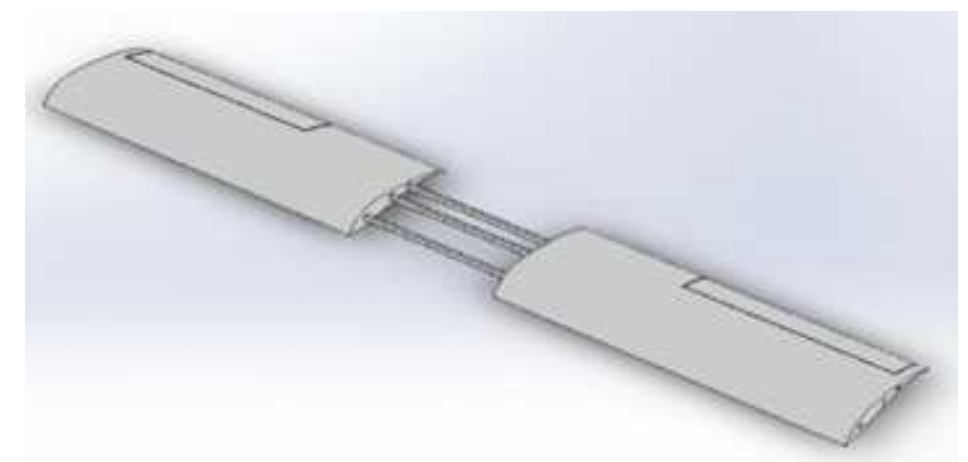

Figure 2: Wing CAD Model.

\section{Fuselage}

The fuselage of the prototype is fabricated with 2.5 in thickness thermocol. The body was entirely hand crafted for superior finishing and to satisfy the requirements. The size of the fuselage was determined based on the pay load and electronic requirement and the length of the fuselage was determined based on the tail moment arm distance.[12] 
The two main divisions inside the fuselage are

- Electronics bay

- Payload bay

For electronics bay a sideway access was provided.

For payload bay rear end access was provided

Fuselage Design Details

- $\quad$ Fuselage length $=1.74 \mathrm{~m}$.

- Rectangular cross section.

- $\quad$ Tapered from the length of $0.96 \mathrm{~m}$

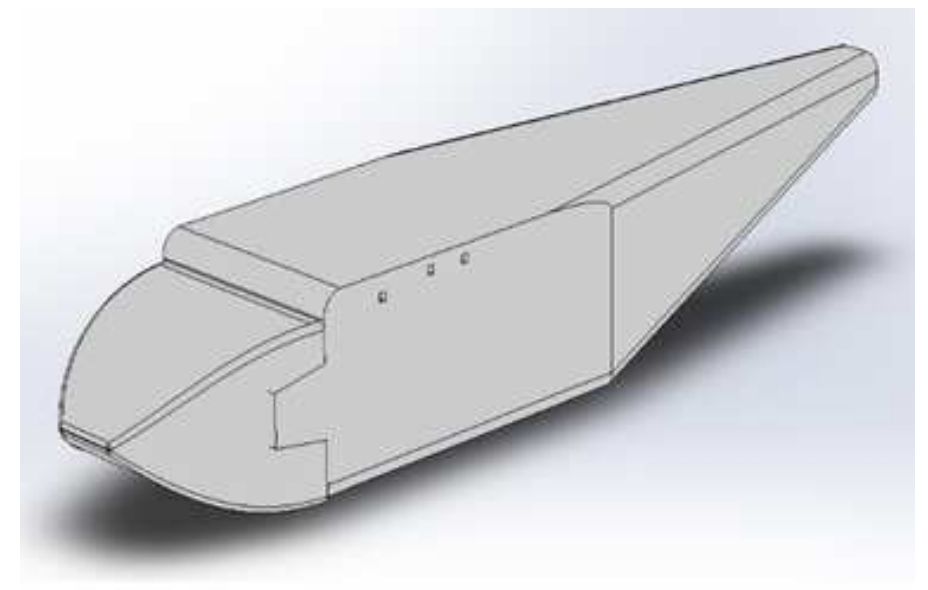

Figure 3: Fuselage CAD Model.

\section{Empennage}

As said in the earlier unit inverted T-tail configuration is selected. Airfoil for the horizontal and vertical stabilizer was selected by calculating Reynolds number. Normally symmetric airfoils are used for horizontal and vertical stabilizer hence NACA-009 was selected. The dimensions of the tail section are given below.

\section{Calculations}

Based on historical data [11]

- $\quad$ Horizontal stabiliser $\left(\mathrm{AR}_{\mathrm{H}}\right)=3.5$

- $\quad$ Vertical stabiliser $\left(\mathrm{AR}_{\mathrm{V}}\right)=1.5$

- $\mathrm{S}_{\mathrm{H}}=0.2314 \mathrm{~m}^{2}$

- $\quad \mathrm{AR}_{\mathrm{H}}=\frac{b 2}{S H}$

- $\mathrm{b}_{\mathrm{H}}=0.89 \mathrm{~m}$

For ease of fabrication $b_{H}$ is taken to be $0.9 m$ 
- $\mathrm{C}_{\mathrm{H}}=0.26 \mathrm{~m}$

For ease of fabrication $\mathrm{C}_{\mathrm{H}}$ is taken to be $0.3 \mathrm{~m}$

- $\quad \mathrm{AR}_{\mathrm{v}}=1.5 \mathrm{~m}$

- $\quad \mathrm{S}_{\mathrm{V}}=0.1157 \mathrm{~m}^{2}$

- $\quad \mathrm{AR}_{\mathrm{V}}=\frac{b 2}{s v}$

- $\quad b_{\mathrm{V}=} 0.41 \mathrm{~m}$

For ease of fabrication $b_{\mathrm{V}}$ is taken to be $0.45 \mathrm{~m}$

- $\mathrm{C}_{\mathrm{v}}=0.28 \mathrm{~m}$

For ease of fabrication $\mathrm{C}_{\mathrm{v}}$ is taken to be $0.3 \mathrm{~m}$

- $\lambda=0.63$

- $\mathrm{C}_{\mathrm{tv}}=0.195 \mathrm{~m}$

- $\mathrm{C}_{\mathrm{rv}}=0.2505 \mathrm{~m}$

- $\mathrm{C}_{\mathrm{avg}}=0.306 \mathrm{~m}$

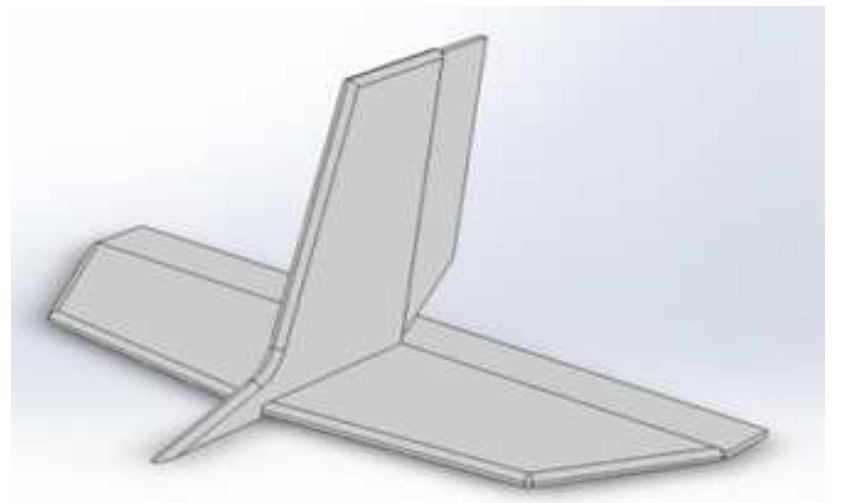

Figure 4: Empennage CAD Model.

\section{ANALYSIS}

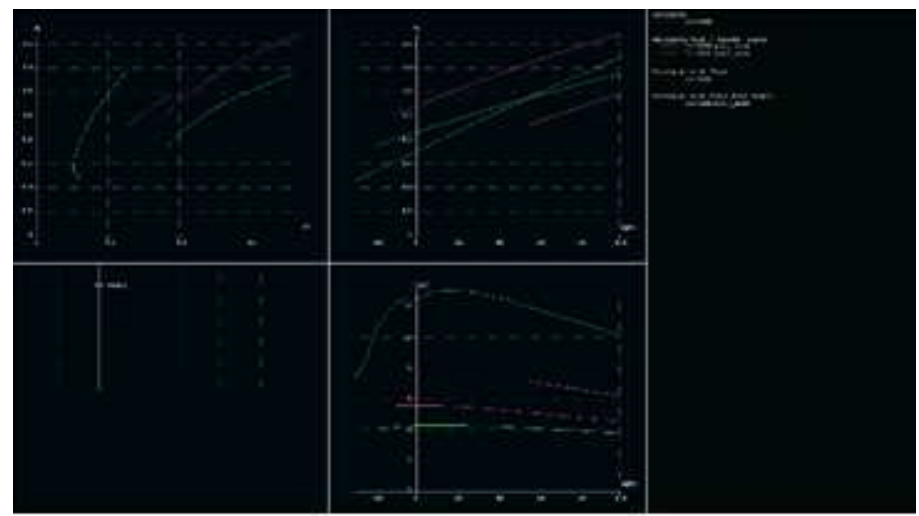

Figure 5: Aircraft Characteristic Analysis. 
Here the wing and the empennage was modelled and analysed for a Reynolds number of 2,50,000. In this graph $\mathrm{Cl}$ vs $\mathrm{Cd}, \mathrm{Cl}$ vs alpha and $\mathrm{Cd}$ vs alpha was observed to be in the optimal range.

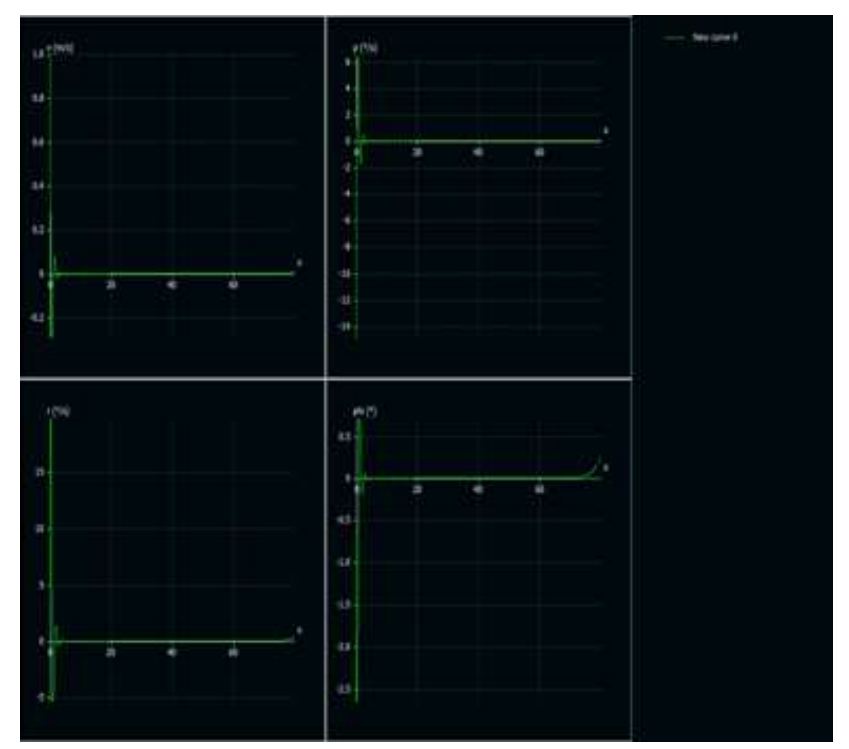

Figure 6: Stability Analysis.

In this graph the time required by the aircraft to come to neutral position after deflection is observed. It is around 4 seconds for the aircraft to recover form forced yaw motion.[12]

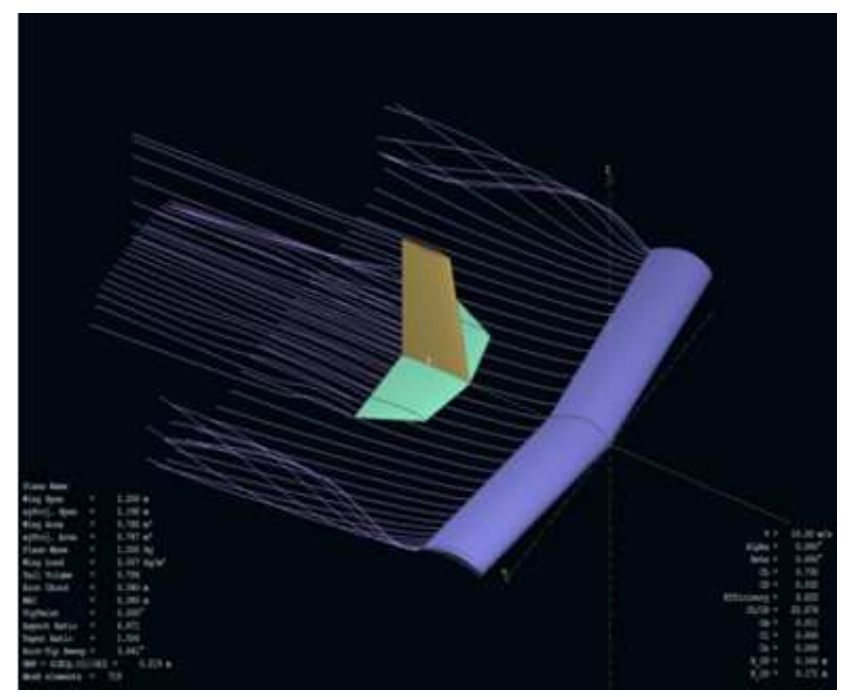

Figure 7: Air Stream Analysis.

In this analysis the air flow around the surface of the wing and empennage is observed here the high-pressure air and low-pressure air mixes at the tip of the wing. This results in vortex and it leads to more drag.

\section{PROPULSION}

As per the requirement of the flight thrust should be at least half of the weight. The team considered the weight and wing loading to decide the motor and propeller. The motor we selected was giving appropriate thrust for 4 cell configuration. 


\section{Load Test Report}

\begin{tabular}{|c|c|c|c|c|c|}
\hline Prop (inch) & Voltage (V) & $\begin{array}{l}\text { Load } \\
\text { Curre }\end{array}$ & Pull (g) & Power(W) & $\begin{array}{l}\text { Efficiency } \\
(\mathrm{g} / \mathrm{W})\end{array}$ \\
\hline $9 * 6$ & 14.8 & 49 & 2500 & 780 & 3.359 \\
\hline $10 * 45$ & 14.8 & 55 & 2800 & 850 & 3.553 \\
\hline $11 \% 55 \mathrm{SF}$ & 14.8 & 60 & 3000 & 950 & 3.837 \\
\hline
\end{tabular}

Based on this graph the team selected 1047 propeller and 14.8 voltage.

The design details are listed as follows:

- $\quad$ Brushless Motor: RPM/V - 925rpm

- $\quad$ Number of motors $=2$

- $\quad$ Prop: Electric Flight Prop 10*4.5

- $\quad$ ESC: $80 \mathrm{~A}$

- $\quad$ Number of ESC $=2$

- $\quad$ Number of battery cells: 4

- $\quad$ Battery Voltage: $14.8 \mathrm{~V}$

- $\quad$ Peak discharge of battery: $25 \mathrm{C}$

- $\quad$ Battery Discharge plug: XT60

\section{FABRICATION}

The type of material being used is hardened thermocol. The thermocol was cut into airfoil shape using hot wire method. The team custom built their own hot wire cutter which has a cutting wire length of $2 \mathrm{~m}$. This method yields very accurate airfoil section.

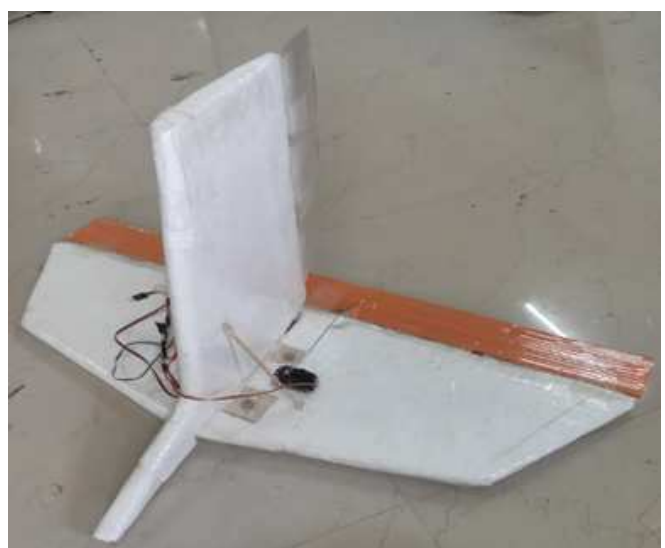

Figure 8: Empennage Section. 


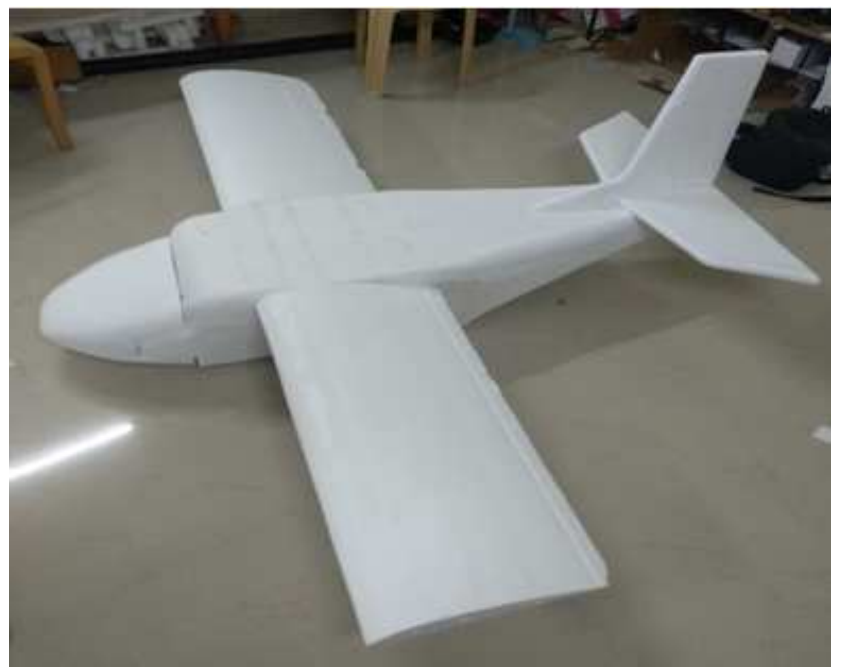

Figure 9: Complete Aircraft before Installing Electronics.

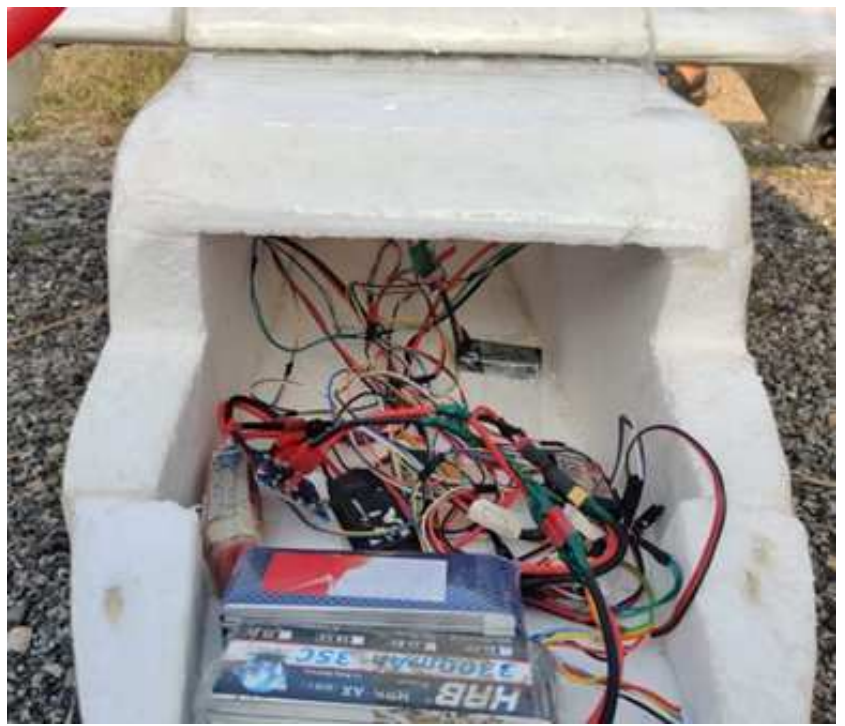

Figure 10: Autonomous Components and Electronics Wiring.

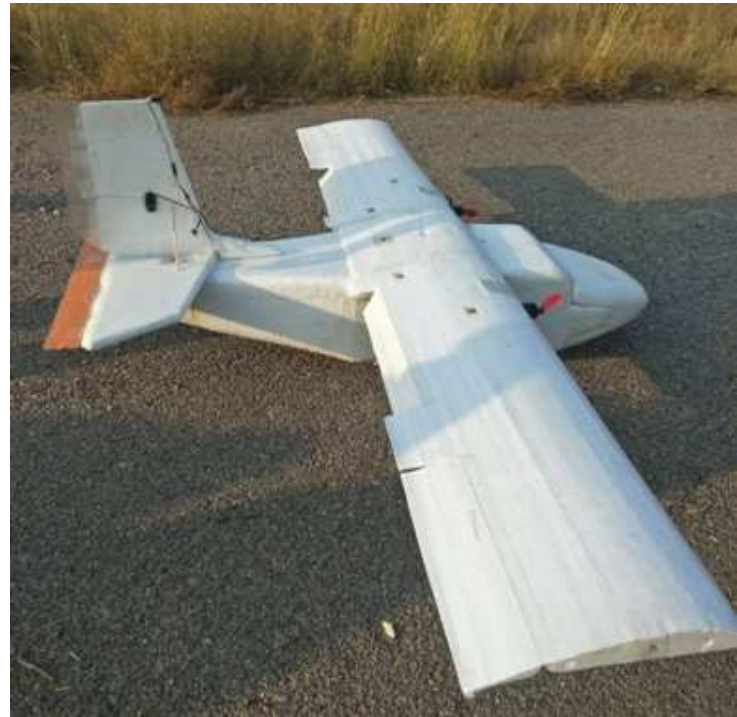

Figure 11: Complete Aircraft Assembled. 


\section{AUTONOMOUS SYSTEM}

With the completion of fabrication, the team successfully flight tested the aircraft with manual controls. For the autonomous flying of the aircraft the team added the flight controller parts to the aircraft. This includes ArdupilotMega 2.8 flight control board, GPS module, telemetry system and power module. The APM 2.8 is a flight controller uses 6 DOF Accelerometer/Gyro MPU-6000 to stabilize the aircraft. It also uses GPS for positional readings. The team employed the control board and calibrated it according to the aircraft using the Mission Planner software. The team added an Arduino Uno board and a program was written to open and close the payload bay.

The final autonomous test flight was conducted and the aircraft was found to be performing according to requirement.

\section{FUTURE SCOPE}

- Computer integrated image processing system can be used for identification of people.

- Improvement in the battery technology helps in increasing the range of the system.

- Higher level telemetry equipment can be used for long range delivery and surveillance. The system can be made completely sustainable.

\section{RESULT}

The team began to fabricate a prototype after having discussions going through literature surveys and conducting various mathematical analysis for verification. The theoretical calculation results and analysis values were appreciably close. The study showed the performance increase by a flight time of 3 minutes at maximum take-off weight (MTOW) of $7 \mathrm{~kg}$. The team employed first person camera system in the aircraft for surveillance purpose.

\section{REFERENCES}

1. T. P. Defelice and D. Axisa, "Modern and prospective technologies for weather modi fi cation activities: Developing a framework for integrating autonomous unmanned aircraft systems,” Atmos. Res., vol. 193, no. April, pp. 173-183, 2017.

2. Z. Yu, Y. Zhang, and Y. Qu, "ScienceDirect tanker Fault-Tolerant Control for Autonomous Control for Autonomous Control for Autonomous Aerial Refueling against Actuator Fault in Fault-Tolerant Control for Autonomous Aerial Refueling against Actuator Fault in Aerial Refueling against Actuator Fault in UAV against Actuator Fault in Receiver UAV Receiver," IFACPapersOnLine, vol. 51, no. 24, pp. 274-279, 2018.

3. Ion, Ababii, et al. "Pilot Cross-Sectional Telephone Survey Test Mainly Based on the Us Brfss's Protocol Conducted in the Republic of Moldova: Challenges of the Surveillance Quality."International Journal of Humanities and Social Sciences (IJHSS) 5.6, Oct - Nov 2016; 73-80

4. F. Nava, C. J. Scheytt, T. Zwick, M. Pauli, G. Benjamin, and W. Winkler, "Ultra-compact 122GHz Radar Sensor for Autonomous Aircrafts," vol. 26, pp. 399-404, 2016.

5. Ganesh, M. "Design of Airship for Aerial Surveillance and Communication Using Knowledge Based Engineering." International Journal of Mechanical and Production Engineering Research and Development (IJMPERD) 8.1 (2018): 17-26.

6. J. Pienillzek, “Re-Configurable Control System for Autonomous Unmanned Aircraft Jacek Pienillzek,” pp. 307-312, 2003. 
7. S. Ffirst and E. Dickmanns, “Autonomous Systems A vision based navigation system for autonomous aircraft," vol. 8890, no. 99, 1999.

8. A. De Bruin, T. Jones, T. Jones, A. De, and B. Thomas, "ScienceDirect of a of a Accurate Autonomous Landing under of a a Fixed-Wing Aircraft under Conditions Conditions Conditions," IFAC-PapersOnLine, vol. 49, no. 17, pp. 170-175, 2016.

9. H. Zhu and L. Deng, "A landmark-based navigation method for autonomous aircraft," Opt. - Int. J. Light Electron Opt., no. 2015, pp. 10-13, 2016.

10. S. Hansen and M. Blanke, "In-flight Fault Diagnosis for Autonomous Aircraft via Low-rate Telemetry Channel," 2012.

11. G. Cai, J. Dias, and L. Seneviratne, "A Survey of Small-Scale Unmanned Aerial Vehicles: Recent Advances and Future Development Trends," no. 2, 2014.

12. S. S. Rao, D. Shrinivasa, T. N. Harshith, and Y. B. Nandan, "Design and Fabrication of Unmanned Surveillance Aeromobile," no. $5,2017$.

13. Zabbar, MdAjijulBin, and ChistyNafiz Ahmed. "Design \& Implementation of an Unmanned Ground Vehicle (UGV) Surveillance Robot." International Journal of Electrical and Electronics Engineering (IJEEE) 5.6 (2016): 2278-9944.

14. Mohammad, H. Sadraey. "Aircraft design: A systems engineering approach." Daniel Webster College, New Hampshire, USA, Aerospace September (2012).Sadraey, Mohammad H. Aircraft design: A systems engineering approach. John Wiley \& Sons, 2012.

15. TAMILSELVAN, S., and G. Nithya."Secure Authentication System Using Video Surveillance."International Journal of Mechanical Engineering (IJME) 2.3, July 2013, 45-54

16. Austin, Reg. Unmanned aircraft systems: UAVS design, development and deployment. Vol. 54. John Wiley \& Sons, 2011. 